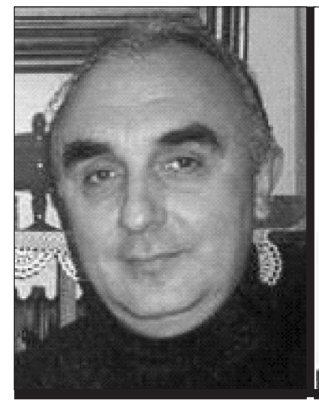

George Pavlou

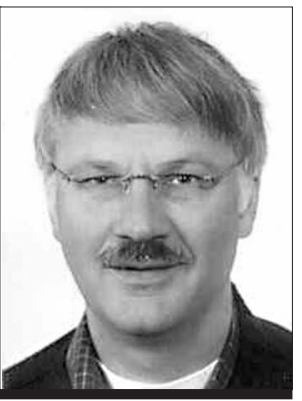

Aiko Pras

\title{
TOPICS IN NETWORK AND SERVICE ManagemENT
}

his is the seventh issue of the series on Network and Service Management that is published twice a year, typically in April and October, although the previous issue had to be published in May (i.e., it was delayed by a month). The series provides articles on the latest developments in this wel established discipline, highlighting recent research achievements and providing insight into both theoretical and practical issues related to the evolution of the discipline from different perspectives. The series provides a forum for the publication of both academic and industrial research, addressing the state of the art, theory, and practice in network and service management.

An important recent development in the community was the change of chairmanship in the IFIP WG6.6, the working group on the Management of Networks and Distributed Systems. Professor Raouf Boutaba of the University of Waterloo, Canada, stepped down as chair of IFIP WG6.6 after serving two terms of three years each. Under Raouf's active leadership, the flagship management conferences Integrated Management (IM) and Network Operations and Management Symposium (NOMS) became more valuable to the community, and previously self-standing events such as DSOM, MMNS, and IPOM got integrated into Manweek. In addition, the new IEEE Transactions on Network and Service Management (TNSM) was launched. After a call for nominations, Prof. Boutaba's tasks were collectively taken over by Dr. Aiko Pras of the University of Twente, Netherlands, (Chair) and Dr. Olivier Festor of INRIA, France (Vice-Chair); you may note that Dr. Pras is also co-editor of this series. The new chairs plan to continue the organization of successful events such as IM and NOMS, as well as smaller events such as DSOM, MMNS, and others. Key to the success of these events has been good collaboration with the IEEE Communications Society sister organization CNOM: the Committee on Network Operations and Management. Under the leadership of the new chairs, this successful collaboration will be continued, as well as coordination and cooperation with other IFIP working groups.

Another important development for the community has been the completion of two and a half years of integration work of the European EMANICS project on Management of the Internet and Complex Services at the end of December 2007. This is a European Network of Excellence that brings together 13 research institutions active in the management of the future Internet. It encompasses work areas dealing with integration (long-term vision, virtual laboratory and testbeds), dissemination (a new European conference discussed later, electronic dissemination, training and technology transfer, open source initiatives), and joint research activities (scalable, economic, and autonomic management). For more information, visit the project site: http://www.emanics.org/. You will also find there a newsletter with community news, events, and developments, which is published roughly three times a year. EMANICS has also established a European conference on Autonomous Infrastructure Security \& Management (AIMS). The second AIMS conference took place in Bremen, 1-3 July 2008: http://www.aims2008.org/. Collocated with AIMS, the EMANICS workshop "Vision and Management of the Future Internet" took place 4-5 July 2008: h t t p : / / e m a n i c s . o r g / c o n t e n t / view/131/135/.

It is also worth noting that one of the key annual events in this area, Manweek 2008, was held 22-26 September on Samos Island, Greece, and included, among other events, the 19th IFIP/IEEE International Workshop on Distributed Systems: Operations and Management (DSOM 2008), the 11th IFIP/IEEE International Conference on Management of Multimedia and Mobile Networks and Services (MMNS 2008), the 8th IEEE International Workshop on IP Operations and Management, and the 3rd IEEE International Workshop on Modeling Autonomic Communications Environments. The next key annual event is the 11th IEEE/IFIP Integrated Management Symposium (IM 2009), which will take place 1-5 June 2009 in New York, New York. IM together with NOMS constitute the premier annual event in network and service management.

Finally, we should mention that the next issue of this series has invited papers addressing the management of the future Internet. Given that in the United States there are initiatives such as FIND and GENI; in Europe there are the Future Internet Assembly and the FIRE program; and in Japan there is NWGN, there is considerable current interest in the future Internet and its management. The 
next issue has solicited papers presenting a vision regarding the management of the future Internet.

We again experienced an overwhelming interest in the seventh issue, receiving 18 submissions in total ( 2 major revisions and 16 new articles). For each paper we got at least three and sometimes four independent reviews. We finally selected four articles, resulting in an acceptance rate of 22.2 percent. It should be mentioned that the acceptance rate for all the previous issues has ranged between 19 percent and 25 percent, making this series a highly competitive place to publish. We intend to maintain our rigorous review process in future issues, thus maintaining the high quality of the published articles.

The first article, "Advanced Network Monitoring Brings Life to the Awareness Plane" by Kind, Denazis, Dimitropoulos, and Claise, presents a survey of the latest advances in traffic measurement targeted at automatically building and maintaining a distributed, self-organizing monitoring layer described as the awareness plane, which is crucial for autonomic service and network management.

The second article, "Business-Driven IT management - Upping the Ante of IT: Exploring the Linkage between IT and Business to Improve Both IT and Business Results" by Moura, Bartolini, and Sauvé, introduces business-driven IT management (BDIM) as a new approach to managing IT systems that uses business measures such as profit, cost, and customer experience in addition to technical metrics such as response time and throughput.

The third article, "Measurement of Download and Play and Streaming IPTV Traffic" by Won, Choi, Hong, Hwang, and Yoo, discusses the download and play IPTV delivery scheme as an interim solution for video on demand, and provides the traffic impact analysis and network-centric quality from the perspective of customers using real-world commercial traces in various user scenarios.
Finally, the fourth article, "Challenges and Opportunities in Managing Maritime Networks" by Kidston and Kunz, presents first the characteristics of maritime networks, which consist of constantly powered mobile wireless nodes with fixed satellite access, and discusses issues in managing such networks, focusing on automation and resource optimization.

We hope that readers of this issue again find the articles informative, and we will endeavor to continue with similar issues in the future. We would finally like to thank all the authors who submitted articles to this series and the reviewers for their valuable feedback and comments on the articles.

\section{BIOGRAPHIES}

GEORGE PAVLOU (g.pavlou@ee.ucl.ac.uk) is a professor of communication networks in the Department of Electronic and Electrical Engineering, University College London, United Kingdom, where he coordinates the activities of the Networks and Services Research Laboratory. He received a Diploma in engineering from the National Technical University of Athens Greece, and M.Sc. and Ph.D. degrees in computer science from University College London. His research interests focus on network management, networking, and service engineering, including aspects such as traffic engineering, quality of service management, policy-based systems, autonomic networking, multimedia service control, and communications middleware. He has been instrumental in a number of European and U.K. research projectsm and has contributed to standardization activities in ISO, ITU-T, and IETF. He was technical program co-chair of IM '01 and MMNS '08.

AIKO PRAs (a.pras@utwente.nl) is an associate professor in the Departments of Electrical Engineering and Computer Science at the University of Twente, the Netherlands, and a member of the Design and Analysis of Communication Systems Group. He received a Ph.D. degree from the same university for his thesis, Network Management Architectures. His research interests include network management technologies, Web services, network measurements, and accounting. He chairs IFIP Working Group 6.6, Management of Networks and Distributed Systems, and is research leader in the European Network of Excellence EMANICS. He has also contributed to research and standardization activities as a member of the Internet Research Task Force (IRTF) Network Management Research Group (NMRG). He was technical program co-chair of IM '05), and is a Steering Committee member of the IFIP/IEEE NOMS and IM Symposia. 